\title{
Leadership \& Professional Development: Sponsored- Catapulting Underrepresented Talent off the Cusp and into the Game
}

\author{
Nancy D Spector, MD ${ }^{1 *}$; Barbara Overholser, $\mathrm{MA}^{2}$
}

${ }^{1}$ Professor of Pediatrics, Executive Director, Executive Leadership in Academic Medicine, Associate Dean of Faculty Development, Drexel University College of Medicine, Philadelphia, Pennsylvania; ${ }^{2}$ Communications and Relationship Manager, ELAM Program, Drexel University College of Medicine, Philadelphia, Pennsylvania.

"When you've worked hard, and done well, and walked through that doorway of opportunity, you do not slam it shut behind you. You reach back and you give other folks the same chances that helped you succeed."

\section{-Michelle Obama}

We are at a point in time where awareness around the existing disparities in gender equity in academic medicine couldn't be higher. It is time for us to take this knowledge and move swiftly into action. What's one of the best ways to do this? Become a sponsor or be sponsored. "Sponsorship can effectively catapult nascent talent from unknown to rising-star status." 1

Catapult-an excellent and fitting word to describe the effect sponsorship can have on careers. Women start out behind and often remain behind men, even with mentoring. ${ }^{2}$ With the catapult of sponsorship, however, high-level career advancement is attainable. Studies show that sponsorship is significantly associated with success: $72.5 \%$ of men and $59.0 \%$ of women who reported sponsorship were successful, compared with $57.7 \%$ and $44.8 \%$ who did not report sponsorship. ${ }^{3}$ For women and underrepresented minorities, sponsorship is especially important and can "dramatically overcome many of the tripwires to achievement." ${ }^{\prime 4}$

Sponsorship is a two-way proposition —and both the sponsor and protégé have responsibility to make the relationship successful. Want to be sponsored? Here's what to do: (1) Broadcast your achievements. You don't have to be a braggart, but you don't need to be humble_celebrate and share your achievements within and outside your network. (2) Seek out leaders of different backgrounds—sponsors don't need to be just like you.

*Corresponding Author: Nancy D. Spector, MD; E-mail: Nds24@drexel.edu; Telephone: 215-991-8240; Twitter: @ELAMProgram

Received: March 25, 2019; Accepted: March 26, 2019

๑) 2019 Society of Hospital Medicine DOI 10.12788/jhm.3214
Varied viewpoints bring broader perspectives to the challenges ahead as you climb the leadership ladder. (3) Clearly spell out your leadership goals for yourself and a potential sponsor. Then work to achieve your shared goals in a timely way.

Consider how you can be a sponsor, particularly for junior faculty and those from under-represented groups. Ask yourself: Who have you sponsored this week? Whose success have you celebrated this quarter? Who will you nominate for an award or recognition this year?

Sponsorship is an essential component of good leadership. Individual leaders and academic health centers (AHCs) must take a step forward toward equity by making sponsorship an expectation and strategic priority. Set the expectation that senior leaders will act as sponsors, set clear goals to work toward (ie, more female chairs, increasing recruitment and retention of underrepresented minorities, etc.), and track metrics. ${ }^{2}$ While "pay it forward" may seem cliché, sponsorship can truly be a remarkable opportunity for growth for both the sponsor and the protégé, and a winning proposition for the institution.

Disclosures: Dr. Spector reports other from I-PASS Patient Safety Institute, outside the submitted work; and she is a co-founder and holds equity in the I-PASS Patient Safety Institute and the Executive Director of Executive Leadership in Academic Medicine. Ms. Overholser has nothing to disclose.

\section{References}

1. Sponsorship: A Path to the Academic Medicine C-suite for Women Faculty? Elizabeth L. Travis, PhD, Leilani Doty, PhD, and Deborah L. Helitzer, ScD. Acad Med. 2013;88(10):1414-1417. doi: 10.1097/ACM.0b013e3182a35456.

2. Foust-Cummings, Dinolfo $S$, Kohler K. Sponsoring Women to Success. https://www.catalyst.org/research/sponsoring-women-to-success/. Accessed May 10, 2019

3, Patton EW, Griffith KA, Jones RD, Stewart A, Ubel PA, Jagsi R. Differences in mentor-mentee sponsorship in male vs female recipients of national institutes of health grants. JAMA Intern Med. 2017;177(4):580-582. doi: 10.1001/ jamainternmed.2016.9391.

4. Hewlett SA. Celebrating Sponsors -- and Sponsorship. Inc. https://www.inc. com/sylvia-ann-hewlett/celebrating-sponsors-and-sponsorship.html. Accessed May 10, 2019. 